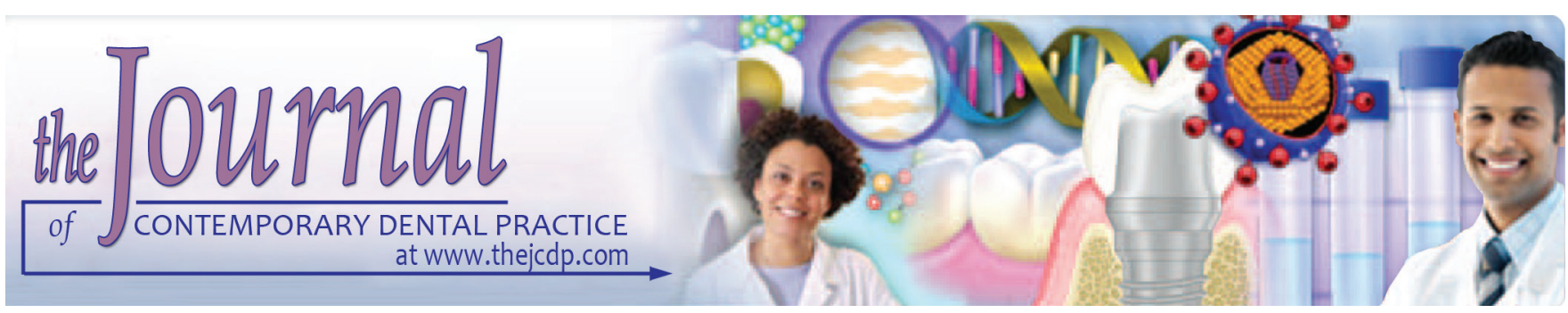

\title{
Assessing the Risk of Oral Cancer associated with Gutka and Other Smokeless Tobacco Products: A Case-control Study
}

${ }^{1} \mathrm{KH}$ Awan, ${ }^{2} \mathrm{QA}$ Hussain, ${ }^{3}$ Shankargouda Patil, ${ }^{4}$ Mahesh Maralingannavar

\begin{abstract}
Introduction: Tobacco and tobacco-related products have been attributed to be causative factors for oral cancer. Newer, chewable, and commercially available smokeless tobacco (ST) products, such as gutka pose further threat in this direction. The aim of the study was to evaluate the risk of oral cancer associated with gutka and other ST products.
\end{abstract}

Materials and methods: A case-control study of 134 cases and 134 controls, over a period of 6 months (July-December 2014), was carried out at the Baqai University, Karachi, Pakistan. An interview-based questionnaire was used to collect data on sociodemographic characteristics, oral hygiene practices and type, duration, and frequency of use of tobacco-related products. Data were analyzed using the Pearson's chi-square $\left(\chi^{2}\right)$ test with the level of significance set as $p<0.05$.

Results: Gutka showed the highest odds ratio toward developing oral cancer ratio among all the tobacco-related products [odds ratio (OR) 5.54; 95\% Cl 2.83-10.83; $p<0.001$ )]. Participants who consumed other ST products also showed 2 to 4 times higher odds ratio of developing oral cancer than compared to those who did not consume these products.

Conclusion: The study provided strong evidence that gutka and other ST products are independent risk factors for oral cancer.

Clinical significance: This study highlights the strong association of different types of ST and oral cancer. This results

\footnotetext{
1,2Department of Oral Medicine and Diagnostic Sciences College of Dentistry, King Saud University, Riyadh, Kingdom of Saudi Arabia

${ }^{3,4}$ Department of Oral and Maxillofacial Surgery and Diagnostic Sciences, Division of Oral Pathology, College of Dentistry Jazan University, Jazan, Kingdom of Saudi Arabia

Corresponding Author: KH Awan, Department of Oral Medicine and Diagnostic Sciences, College of Dentistry, King Saud University, Riyadh, Kingdom of Saudi Arabia, Phone: +096614677422, e-mail: kamranhabibawan@gmail.com
}

in identification of high-risk groups for targeted screening for potential oral cancer lesions.

Keywords: Betel quid, Case-control, Gutka, Oral cancer, Smokeless tobacco.

How to cite this article: Awan $\mathrm{KH}$, Hussain QA, Patil $\mathrm{S}$, Maralingannavar M. Assessing the Risk of Oral Cancer associated with Gutka and Other Smokeless Tobacco Products: A Case-control Study. J Contemp Dent Pract 2016;17(9): 740-744.

\section{Source of support: Nil}

Conflict of interest: None

\section{INTRODUCTION}

Oral cancer is the sixth most common cancer globally; however, the incidence is much higher in the developing countries, including Pakistan, India, Sri Lanka. ${ }^{1,2}$ In Central and Southeast Asia, oral cancer accounts for up to $40 \%$ of all cancers compared to less than $4 \%$ reported in most developed countries. ${ }^{3,4}$ The etiology of oral cancer is multifactorial with majority of the cases attributable to separate and combined use of tobacco (smoked and smokeless), excessive alcohol consumption, betel quid, and betel quid substitutes. ${ }^{5-9}$

Smokeless tobacco (ST) is referred to as tobacco products that are consumed by means other than smoking and include chewing, sniffing, placing the tobacco between the gums and teeth and application to the skin. Smokeless tobacco are broadly categorized into two main types: Chewing tobacco and snuff..$^{10}$ Chewing tobacco is universally available in the form of loose, cut, and shredded leaf whereas snuff is available as fine ground tobacco that can be dry, moist, or in sachets. Different names are given to various ST products depending on where they are used, 
such as gutka, betel quid, supari, khaini, mawa, qiwam, mainpuri, zarda, naswar, nass, gul, mishri, gudakhu, shammah, toombak, plug, iq'mik and snus.

In Pakistan, oral cancer is a cause of great concern and a major threat to public health. The oral cancer incidence rates are the highest in Pakistan and as a result makes it the second most common cancer among both males and females. ${ }^{11,12}$ This high incidence is mainly attributed to the use of different forms of ST products including gutka and betel quid. ${ }^{13}$ Gutka is a type of ST that contains powered tobacco, areca nut, slaked lime, catechu, and condiments. Other substances, particularly spices, including cardamom, saffron, cloves, aniseed, turmeric, mustard, or sweeteners are added according to local preferences. Gutka started as custom-mixed product available from paan vendors; however, now it is commercially manufactured and distributed in the form of cheap and attractive sachets. The ease of availability, favorable taste, and low cost made it more popular among all age groups, even the primary school children. ${ }^{14}$ Gutka have been found to be highly addictive in comparison to other chewing tobacco products and a first step to smoking. ${ }^{15}$ Studies in India have reported that five million children under the age of 15 years are addicted to gutka. ${ }^{15}$

Recently with increased availability and use of many different forms of ST products, it has become imperative to evaluate their harmful effects. Moreover, there is a paucity of data on research related to new tobacco products, especially related to gutka. There are not many studies in the published literature that have reported evidences on risk of oral cancer related to gutka. Therefore, the aim of the present study was to investigate the risk of oral cancer associated with gutka and other ST products and report any association between oral cancer and these products.

\section{MATERIALS AND METHODS}

\section{Study Design}

A hospital-based, unmatched case-control study was carried out at Baqai Dental College, Karachi, Pakistan over a period of 6 months from July 2014 to December 2014. Patients diagnosed with oral cancer were included in the study as cases, whereas patients in the Department of General Medicine at Baqai Hospital, Karachi, Pakistan were included as controls. Approval for the study was obtained from the Institutional Research and Ethics Committee. The study was performed in accordance with the Helsinki Declaration, as revised in 2000. Standard procedures of informed consent inclusive of anonymity and confidentiality were observed.

\section{Study Participants}

The case group consisted of patients aged 18 years and above with histopathologically confirmed diagnosis of oral cancer. All cases that had confirmed diagnosis of oral cancer and visited the hospital during the study period were included. Cases that had metastatic oral lesions, tumors of the soft palate, uvula, and major salivary glands were excluded.

The control group consisted of age-matched ( \pm 5 years) patients who visited the Department of General Medicine during the study period and had no known history of oral cancer. Those who had any other malignancy and/or medically compromised were excluded.

\section{Instrument and Data Collection}

All the participants were interviewed by the investigator (KHA) using a structured and standardized questionnaire. The questionnaire was peer-reviewed, piloted, and was found comprehensive. The questionnaire consisted of three sections: (i) The first section collected the demographic details of the participants, i.e., age, gender, level of education, occupation, and oral cancer site; (ii) the second section consisted of questions on oral hygiene practices; and (iii) the last section collected the data on the anticipated risk factors and comprised of questions on the type, frequency, and duration of the habits.

\section{Data Analysis}

Data was analyzed using Statistical Package for the Social Sciences (SPSS), released 2009; PASW Statistics for Windows, Version 18.0. Chicago: SPSS Inc. The responses were coded as numeric in order to facilitate the data entry. Univariate logistic regression was done for identifying the risk factors and adjusting for the confounding variables. The results were analyzed using the Pearson's chi-square $\left(\chi^{2}\right)$ test with the level of significance set as $p<0.05$.

\section{RESULTS}

A total of 268 subjects (134 cases and 134 controls) with the mean age of 46.9 years ( $S D \pm 13.10$ years) volunteered to participate in the study. Majority of the study participants were in the age range of 41 to 50 years. In the study population, $81.7 \%(n=219)$ of the participants were males. Among the case group, more than half of the cases has cancer on the tongue (56.7\%), followed by buccal mucosa $(38.8 \%)$. Palate and lip were the least common site of oral cancer among the case group. Table 1 shows detailed demographic data of the study participants.

Among the case group, gutka was the most commonly used product contributing to more than one-third of the cases (Table 2). On the contrary, less than $10 \%$ of 
Table 1: Demographic data of the study participants

\begin{tabular}{lll}
\hline Variables & Cases $n$ (\%) & Controls $n$ (\%) \\
\hline Gender & $109(81.3)$ & $110(82.1)$ \\
Male & $25(18.7)$ & $24(17.9)$ \\
Female & & \\
Age group & $11(8.2)$ & $13(9.7)$ \\
18-30 & $32(23.9)$ & $30(22.4)$ \\
$31-40$ & $42(31.3)$ & $33(24.6)$ \\
$41-50$ & $37(27.6)$ & $32(23.9)$ \\
$50-60$ & $12(8.9)$ & $26(19.4)$ \\
$>60$ & & \\
Level of education & $12(8.9)$ & $8(5.9)$ \\
No education & $78(58.2)$ & $34(25.4)$ \\
Primary education & $32(23.9)$ & $30(22.4)$ \\
Secondary education & $9(6.7)$ & $35(26.1)$ \\
Undergraduate & $3(2.2)$ & $27(20.1)$ \\
Degree or above & & \\
Occupation & $81(60.4)$ & $50(37.3)$ \\
Unskilled & $22(16.4)$ & $54(40.3)$ \\
Skilled & $18(13.4)$ & $20(14.9)$ \\
Unemployed & $13(9.7)$ & $10(7.5)$ \\
Others* & & \\
Site of oral cancer & $52(38.8)$ & - \\
Buccal mucosa & $76(56.7)$ & - \\
Tongue & $2(1.5)$ & - \\
Floor of mouth & $4(2.9)$ & - \\
Others** & & \\
\hline
\end{tabular}

*Included housewives; **Included lesions on palate and lip

the participants among the control group had the habit of gutka chewing. Similarly, the percent of participants using other tobacco-related products was higher among the case group compared to the control group; betel quid (case group $=18.7 \%$ vs control group $=12.7 \%$ ), supari (case group $=14.9 \%$ vs control group $=4.5 \%$ ). Furthermore, there were few participants who reported using more than one tobacco-related products and all of them were among the case group.

The odds ratio of developing oral cancer in participants was higher among the gutka users (OR 5.54; 95\% CI 2.83-10.83; $\mathrm{p}<0.001)$ compared to the participants
Table 2: Distribution of tobacco-related products among the study participants

\begin{tabular}{|c|c|c|c|c|c|c|}
\hline \multirow[b]{2}{*}{ Variables } & \multicolumn{2}{|c|}{$\begin{array}{l}\text { Cases } \\
n=134\end{array}$} & \multicolumn{2}{|c|}{$\begin{array}{c}\text { Controls } \\
n=134\end{array}$} & \multicolumn{2}{|c|}{$\begin{array}{c}\text { Total } \\
n=268\end{array}$} \\
\hline & $n$ & $\%$ & $n$ & $\%$ & $n$ & $\%$ \\
\hline \multicolumn{7}{|l|}{ Smokeless tobacco } \\
\hline Gutka & 50 & 37.3 & 13 & 9.7 & 63 & 23.5 \\
\hline Betel quid & 25 & 18.7 & 17 & 12.7 & 42 & 15.7 \\
\hline Supari & 20 & 14.9 & 6 & 4.5 & 26 & 9.7 \\
\hline Naswar & 16 & 11.9 & 5 & 3.7 & 21 & 7.8 \\
\hline Mainpuri & 13 & 9.7 & 3 & 2.2 & 16 & 5.9 \\
\hline Chewing tobacco & 10 & 7.5 & 2 & 1.5 & 12 & 4.5 \\
\hline Gutka and supari & 11 & 8.2 & 0 & 0 & 11 & 4.1 \\
\hline $\begin{array}{l}\text { Chewing tobacco and } \\
\text { Betel quid }\end{array}$ & 6 & 4.5 & 0 & 0 & 6 & 2.3 \\
\hline \multicolumn{7}{|l|}{ Smoked tobacco } \\
\hline Cigarette & 48 & 35.8 & 46 & 34.3 & 94 & 35.1 \\
\hline Bidi & 23 & 17.2 & 18 & 13.4 & 41 & 15.3 \\
\hline
\end{tabular}

who did not consume gutka (Table 3). Chewing tobacco participants had $5.32(95 \%$ CI 1.14-24.77; $p=0.033)$ times higher odds ratio compared to the participants who did not chew tobacco. Participants who consumed mainpuri, supari, and naswar showed four times higher odds ratio of developing oral cancer than compared to those who did not consume these products. Betel quid users had almost twice the odds ratio (95\% CI 0.80-3.08; $\mathrm{p}=0.181$ ) times of developing oral cancer than nonusers (Table 4).

\section{DISCUSSION}

The emergence of newer, chewable flavored forms of tobacco along with several other ingredients, such as gutka has changed the trends in the tobacco market (Table 5). In Pakistan, an estimated 8 to 10 times increase in the risk of oral cancers has been reported in recent years, mainly due to an increase in use of tobacco-related products. ${ }^{13}$ Further, approximately $40 \%$ of the adolescent and adult population of squatter settlement in Karachi has been reported to be using at least one product of chewable tobacco on a daily basis. ${ }^{16}$ Therefore, the present study

Table 3: Association between consumption of different tobacco-related products and risk of oral cancer

\begin{tabular}{|c|c|c|c|c|c|c|c|c|}
\hline \multirow[b]{2}{*}{ Variables } & \multicolumn{2}{|c|}{ Cases $n=134$} & \multicolumn{2}{|c|}{ Controls $n=134$} & \multirow[b]{2}{*}{ Odds ratio } & \multicolumn{2}{|c|}{$95 \%$ confidence interval } & \multirow[b]{2}{*}{$p$-value* } \\
\hline & $n$ & $\%$ & $n$ & $\%$ & & Lower bound & Upper bound & \\
\hline \multicolumn{9}{|l|}{ Smokeless tobacco } \\
\hline Gutka & 50 & 37.3 & 13 & 9.7 & 5.54 & 2.83 & 10.83 & 0 \\
\hline Betel quid & 25 & 18.7 & 17 & 12.7 & 1.57 & 0.80 & 3.08 & 0.181 \\
\hline Supari & 20 & 14.9 & 6 & 4.5 & 3.74 & 1.45 & 9.64 & 0.006 \\
\hline Naswar & 16 & 11.9 & 5 & 3.7 & 3.49 & 1.24 & 9.84 & 0.017 \\
\hline Mainpuri & 13 & 9.7 & 3 & 2.2 & 4.69 & 1.30 & 16.86 & 0.017 \\
\hline Chewing tobacco & 10 & 7.5 & 2 & 1.5 & 5.32 & 1.14 & 24.77 & 0.033 \\
\hline \multicolumn{9}{|l|}{ Smoked tobacco } \\
\hline Cigarette & 48 & 35.8 & 46 & 34.3 & 1.06 & 0.64 & 1.76 & 0.798 \\
\hline Bidi & 23 & 17.2 & 18 & 13.4 & 1.33 & 0.68 & 2.60 & 0.397 \\
\hline
\end{tabular}

${ }^{*} p<0.05$ statistically significant 
Assessing the Risk of Oral Cancer associated with Gutka and Other Smokeless Tobacco Products: A Case-control Study

Table 4: Odds ratios among users of tobacco-related products

\begin{tabular}{|c|c|c|c|}
\hline Variable & $p$-value & Category & Odds ratio $(95 \% \mathrm{Cl})$ \\
\hline \multirow[t]{5}{*}{$\begin{array}{l}\text { Age when started } \\
\text { the habit (years) }\end{array}$} & 0.09 & $\begin{array}{l}\text { Less } \\
\text { than } 15\end{array}$ & $1.97(0.88-4.39)$ \\
\hline & & $15-20$ & $1.53(0.75-3.15)$ \\
\hline & & $21-25$ & $1.92(0.92-4.0)$ \\
\hline & & $26-30$ & $1.45(0.67-3.13)$ \\
\hline & & $31-35$ & $3.22(1.27-8.13)$ \\
\hline $\begin{array}{l}\text { Tobacco users } \\
\text { in family }\end{array}$ & $<0.001$ & Yes & $1.65(1.33-2.04)$ \\
\hline $\begin{array}{l}\text { Tobacco users } \\
\text { among friends }\end{array}$ & 0.97 & Yes & $1.00(0.81-1.25)$ \\
\hline $\begin{array}{l}\text { Tobacco users } \\
\text { among colleagues }\end{array}$ & 0.001 & Yes & $1.44(1.16-1.79)$ \\
\hline \multirow{3}{*}{$\begin{array}{l}\text { Time product kept in } \\
\text { the mouth (minutes) }\end{array}$} & $<0.001$ & $<30$ & $1.45(0.91-2.31)$ \\
\hline & & $\begin{array}{l}30 \text { or } \\
\text { more }\end{array}$ & $1.33(0.81-2.17)$ \\
\hline & & Overnight & $2.90(1.64-5.16)$ \\
\hline \multirow[t]{2}{*}{$\begin{array}{l}\text { Site at which product } \\
\text { held in mouth }\end{array}$} & 0.001 & $\begin{array}{l}\text { One } \\
\text { place }\end{array}$ & $1.37(0.87-2.08)$ \\
\hline & & $\begin{array}{l}\text { More } \\
\text { than one }\end{array}$ & $1.81(1.18-2.76)$ \\
\hline
\end{tabular}

was carried out to evaluate the risk of these products in developing oral cancer.

In our study, gutka was the most commonly used product among the participants who had oral cancer. Other tobacco-related products, such as betel quid, supari, mainpuri, and naswar were also more common among the participants with oral cancer. Due to a slick, high profile advertising campaign, and aggressive marketing, gutka and other tobacco-related products have become very popular with all sections of Pakistani society, including school children. Since cigarette smoking is still considered a taboo for most children, teenagers, and women in Pakistan, these tobacco-related products provide an alternate source of addiction and are often advertised and marketed as being safer than conventional cigarettes. Furthermore, these products are very cheap and easily accessible to the public, leading to a much higher frequency of use. ${ }^{17}$

The present study showed higher odds ratio of developing oral cancer among the participants who consumed tobacco-related products. The highest odds ratio of developing oral cancer was noted among the participants who were gutka users. Further, all the participants using these tobacco-related products showed higher odds ratio of developing oral cancer compared to the participants who did not consume these products. These findings are in line with previous studies and further fortify the fact that those who consume gutka and other tobacco-related products are at higher risk of developing oral cancer. ${ }^{18-22}$ Interestingly, the participants who consumed more than one tobacco-related products, such as gutka + supari or
Table 5: Major carcinogenic and genotoxic agents in gutka

\begin{tabular}{ll}
\hline Ingredients & Carcinogenic/genotoxic agents \\
\hline Tobacco & NNN, NNK \\
Areca nut & Arecoline, MNPN \\
Areca nut + lime & ROS \\
Catechu + lime & ROS \\
\hline
\end{tabular}

NNN: N'-nitrosonornicotine; NNK: 4-(methylnitrosamino)-1-(3pyridyl)-1-butanone; MNPN: 3-(methylnitrosamino) propionitrile; ROS: Reactive oxygen species, $\mathrm{O}-\cdot \cdot \mathrm{H}_{2} \mathrm{O}_{2}, \mathrm{OH}$

chewing tobacco + betel quid were among the group that had oral cancer. These findings support the fact that the use of more than one type of tobacco-related products have a synergistic effect and significantly increases the risk of oral cancer. ${ }^{17}$

\section{CONCLUSION}

Our results show a significantly higher odds ratio of developing oral cancer among participants who used gutka and/or other tobacco-related products. The use of tobacco with lime, betel quid with or without tobacco, and areca nut have been identified as carcinogenic to humans. As gutka is a mixture of several of these ingredients, their carcinogenic affect can be surmised. Although some recent curbs have been put on the manufacture and sale of these products, urgent actions are needed to permanently ban gutka and other established oral cancer causing tobacco products. In addition, education to reduce or eliminate home-made preparations needs to be accelerated.

\section{REFERENCES}

1. Parkin DM, Whelan SL, Fearlay J, Teppo L, Thomas DB, editors. Cancer incidence in five continents. Vol. VIII. Lyon: IARC Scientific Publications No. 155, IARC Press; 2002.

2. Awan KH, Patil S, Islam SA, Jafer M. Early detection of oral cancer - guidelines for dental practitioners. J Int Oral Health 2016;8(3):399-403.

3. Warnakulasuriya S. Global epidemiology of oral and oropharyngeal cancer. Oral Oncol 2009 Apr-May;45(4-5):309-316.

4. Downer MC. Patterns of disease and treatment and their implications for dental health services research. Community Dental Health 1993 Sep;10 Suppl 2:39-46.

5. Zygogianni AG, Kyrgias G, Karakitsos P. Oral Squamous cell cancer: early detection and the role of alcohol and smoking. Head Neck Oncol 2011 Jan 6;3:2.

6. Lambert R, Sauvaget C, de Camargo Cancela M, Sankaranarayanan R. Epidemiology of cancer from the oral cavity and pharynx. Eur J Gastroenterol Hepatol 2011 Aug;23(8):633-641.

7. International Agency on Research on Cancer. IARC monographs on the evaluation of carcinogenic risks to humans. Betel-quid and areca-nut chewing and some areca-nut related nitrosamines. Vol. 85. IARC; Lyon, France, 2004.

8. International Agency on Research for Cancer. Smokeless tobacco and some tobacco-specific N-nitrosamines. Monographs. Vol. 89. Lyon: IARC; 2007. 
9. Awan KH. Effects of tobacco use on oral health - an overview. Annal Dent Univ Malaya 2011;18:18-23.

10. Warnakulasuriya KA, Ralhan R. Clinical, pathological, cellular and molecular lesions caused by oral smokeless tobacco - a review. J Oral Pathol Med 2007 Feb;36(2):63-77.

11. Camargo CM, Voti L, Guerra M, Chapuis F, Mazuir M, Curado MP. Oral cavity cancer in developed and in developing countries: population-based incidence. Head Neck 2010 Mar;32(3):357-367.

12. Cancer Registry and Clinical Data Management (CRCDM) Shaukat Khanum Memorial Cancer Hospital and Research Center (SKMCH\&RC). Report based on cancer cases registered at SKMCH\&RC from 1994 Dec-2011 Dec and in 2011. Released 2012 Jun. Available from: www.shaukatkhanum.org.pk.

13. Merchant A, Husain SS, Hosain M, Fikree FF, Pitiphat W, Siddiqui AR, Hayder SJ, Haider SM, Ikram M, Chuang SK, et al. Paan without tobacco: an independent risk factor for oral cancer. Int J Cancer 2000 Apr 1;86(1):128-131.

14. Shah SM, Merchant AT, Luby SP, Chotani RA. Addicted school children: prevalence and characteristics of areca nut chewing among primary school children in Karachi, Pakistan. J Paediatr Child Health 2002 Oct;38(5):507-510.

15. Kumar S, Pandey U, Bala N, Tewar V, Oanh KT. Tobacco habit in Northern India. J Indian Med Assoc 2006 Jan;104(1): 19-22, 24.

16. Khawaja MR, Mazahir S, Majeed A, Malik F, Merchant KA, Maqsood M, Malik R, Ghaffar S, Fatmi Z. Knowledge, attitude and practices of a Karachi slum population regarding the role of products of betel, areca and smokeless tobacco in the etiology of head and neck cancers. J Pak Med Assoc 2005:S41.

17. Nair U, Bartsch H, Nair J. Alert for an epidemic of oral cancer due to use of the betel quid substitutes gutka and pan masala: a review of agents and causative mechanisms. Mutagenesis $2004 \mathrm{Jul} ; 19(4): 251-262$.

18. Lee CH, Ko YC, Huang HL, Chao YY, Tsai CC, Shieh TY, Lin LM. The precancer risk of betel quid chewing, tobacco use and alcohol consumption in oral leukoplakia and oral submucous fibrosis in southern Taiwan. Br J Cancer $2003 \mathrm{Feb}$ 10;88(3):366-372.

19. Ariyawardhana A, Athukorala AD, Arulanandam A. Effect of betel chewing, tobacco smoking and alcohol consumption on oral submucous fibrosis: a case control study in Sri Lanka. J Oral Pathol Med 2006 Apr;35(4):197-201.

20. Madani AH, Dikshit M, Bhaduri D. Risk for oral cancer associated to smoking, smokeless and oral dip products. Ind J Public Health 2012 Jan-Mar;56(1):57-60.

21. Nayak AG, Chhaparwal Y, Pai KM. The hazards of gutka chewing. Oral Surg Oral Med Oral Pathol Oral Radiol Endod 2010 Nov;110(5):548.

22. Murti PR, Bhonsle RB, Pindborg JJ. Malignant transformation rate in oral submucous fibrosis over a 17-year period. Community Dent Oral Epidemiol 1985 Dec;13(6): 340-341. 